\title{
Correlation Analysis Between Preoperative Serum Iron Level and Prognosis as Well as Recurrence of HCC After Radical Resection
}

This article was published in the following Dove Press journal: Cancer Management and Research

\author{
Yicheng $\mathrm{Li}^{1,2, *}$ \\ Wentao $\mathrm{Xu}^{\mathrm{l}}{ }^{*} *$ \\ Pu Chen ${ }^{1}, *$ \\ Minjun Liao ${ }^{1,3}$ \\ Wanying Qin' \\ Weijia Liao' \\ Zhaoquan Huang ${ }^{1,4}$ \\ 'Laboratory of Hepatobiliary and \\ Pancreatic Surgery, Affiliated Hospital of \\ Guilin Medical University, Guilin 54100I, \\ Guangxi, People's Republic of China; \\ ${ }^{2}$ Second Clinical Medical College, \\ Guangxi Medical University, Nanning \\ 53002I, Guangxi, People's Republic of \\ China; ${ }^{3}$ Guangxi Medical University, \\ Nanning 53002I, Guangxi, People's \\ Republic of China; ${ }^{4}$ Department of \\ Pathology, Guilin Medical University, \\ Guilin 54100I, Guangxi, People's \\ Republic of China
}

*These authors contributed equally to this work
Background: The purpose of this retrospective study was to investigate the relationship between serum iron levels and the prognosis and risk of recurrence in patients with hepatocellular carcinoma (HCC).

Methods: A total of $253 \mathrm{HCC}$ patients who underwent radical resection were involved in this study.

Results: According to the receiver operating characteristic (ROC) curve, the optimal cut-off value for preoperative serum iron in the assessment of HCC postoperative prognosis was $94 \mathrm{ug} / \mathrm{dL}$. The overall survival (OS) of patients in the high iron group was significantly better than that in the low iron group $(p<0.001)$. The recurrence rate of patients in the low iron group was higher than that in the high iron group $(p=0.011)$. Correlation analysis showed that preoperative serum iron level was correlated with tumor size $>5 \mathrm{~cm}\left(\chi^{2}=11.590, p<0.001\right)$, recurrence $\left(\chi^{2}=5.714, p=0.017\right)$ and microvascular invasion $\left(\chi^{2}=5.087, p=0.024\right)$. In addition, univariate analysis showed that $\mathrm{OS}$ and disease-free survival (DFS) of HCC patients with high iron level were better than those with low iron level. Furthermore, multivariate COX proportional hazards regression analysis showed that serum iron $\leq 94 \mu \mathrm{g} / \mathrm{dL}$, tumor size $>5 \mathrm{~cm}$, and microvascular invasion were independent predictors for shorter OS and DFS in HCC patients after operation, while recurrence was for shorter OS.

Conclusion: Patients with low preoperative serum iron level had worse postoperative survival and higher recurrence rate in HCC. Preoperative serum iron is an independent predictor of HCC patients. For HCC patients with low iron levels, prognosis of patients may be improved if appropriate iron is supplemented.

Keywords: HCC, serum iron, prognosis, recurrence, survival rate

\section{Introduction}

Hepatocellular carcinoma (HCC) is one of the tumors with high incidence in the world, and is the leading cause of cancer-related death worldwide. ${ }^{1}$ Currently, the main clinical treatment methods for HCC are tumor resection, liver transplantation, radiotherapy, chemotherapy and artificial liver therapy. Due to the shortage of liver sources for liver transplantation, radical tumor resection is still the most feasible and effective method at present. $^{2}$ However, the high rate of recurrence and metastasis after HCC surgery and the low medium-long term survival rate are still huge clinical challenges. ${ }^{3}$

Serum alpha-fetoprotein (AFP) is the "gold standard" for the diagnosis and monitoring of $\mathrm{HCC}$, but due to its low sensitivity and specificity in the diagnosis of $\mathrm{HCC}^{4}$ it is not effective in the diagnosis for small hepatocellular carcinoma (SHCC), the ability of AFP to predict postoperative recurrence of HCC is limited. ${ }^{5-7}$ Therefore, it is of
Correspondence: Weijia Liao Pancreatic Surgery, Affiliated Hospital of Guilin Medical University, Guilin 54100I, Guangxi, People's Republic of China Email liaoweijia288@I63.com

Zhaoquan Huang

Department of Pathology, Guilin Medical

University, Guilin 54100I, Guangxi,

People's Republic of China

Email191990449@qq.com 
great significance to explore novel clinical indicators for the evaluation of postoperative prognosis of patients with HCC.

Iron is an essential microelement for the human body, which is involved in the physiological metabolism of the body, and disorder of iron metabolism is reflected in the occurrence of a variety of diseases. ${ }^{8-11}$ Studies have shown that the content of iron in human body is closely related to the occurrence and development of tumors. ${ }^{12,13}$ Iron plays an important role in tumor formation, tumor cell proliferation ${ }^{14}$ and normal cell carcinogenesis, ${ }^{15}$ including liver cancer. ${ }^{16}$ In the liver, increased iron reserves can accelerate liver injury and fibrosis and even increase the possibility of HCC. ${ }^{17}$ However, it is not clear whether the level of serum iron will affect the postoperative survival quality of patients with HCC. This study aims to explore the relationship between serum iron level and the prognosis of HCC, so as to provide an assessment of recurrence risk after radical resection and a non-invasive and convenient detection index for the prognosis of HCC.

\section{Methods}

\section{Subjects}

In our study, $253 \mathrm{HCC}$ patients who underwent radical resection at the Affiliated Hospital of Guilin Medical University were involved. From June 2007 to May 2012, a total of 756 patients were diagnosed with liver cancer in the Affiliated
Hospital of Guilin Medical University, after the exclusion of patients with combined cholangiocarcinoma and secondary liver cancer, 649 patients with HCC that met the diagnostic requirements remains. The diagnosis of HCC patients was mainly based on serological examination (mainly AFP) and imaging examination including computerized tomography (CT), ultrasonography (US) and magnetic resonance imaging (MRI), and all patients were eventually confirmed as HCC by pathological diagnosis. Among these patients with $\mathrm{HCC}$, patients who did not receive surgery, liver transplantation, non-radical resection and other non-conformance were excluded from the cohort, and the final number of patients included in the experimental cohort was 253 (Figure 1). The surgical indications of radical hepatectomy in the research institute were as follows: the patient is in good general condition with no obvious organic lesions of heart, lung, kidney and other important organs; normal or only mildly impaired liver function (Child-Pugh class A); Or the liver function grade is Child-Pugh class B, which is restored to class A after short-term liver protection treatment. Liver reserve function (such as ICGR15) is basically within the normal range; no unresectable metastatic tumor was found.

This study is in line with the declaration of Helsinki principles and has been approved by the research ethics committee of the Affiliated Hospital of Guilin Medical

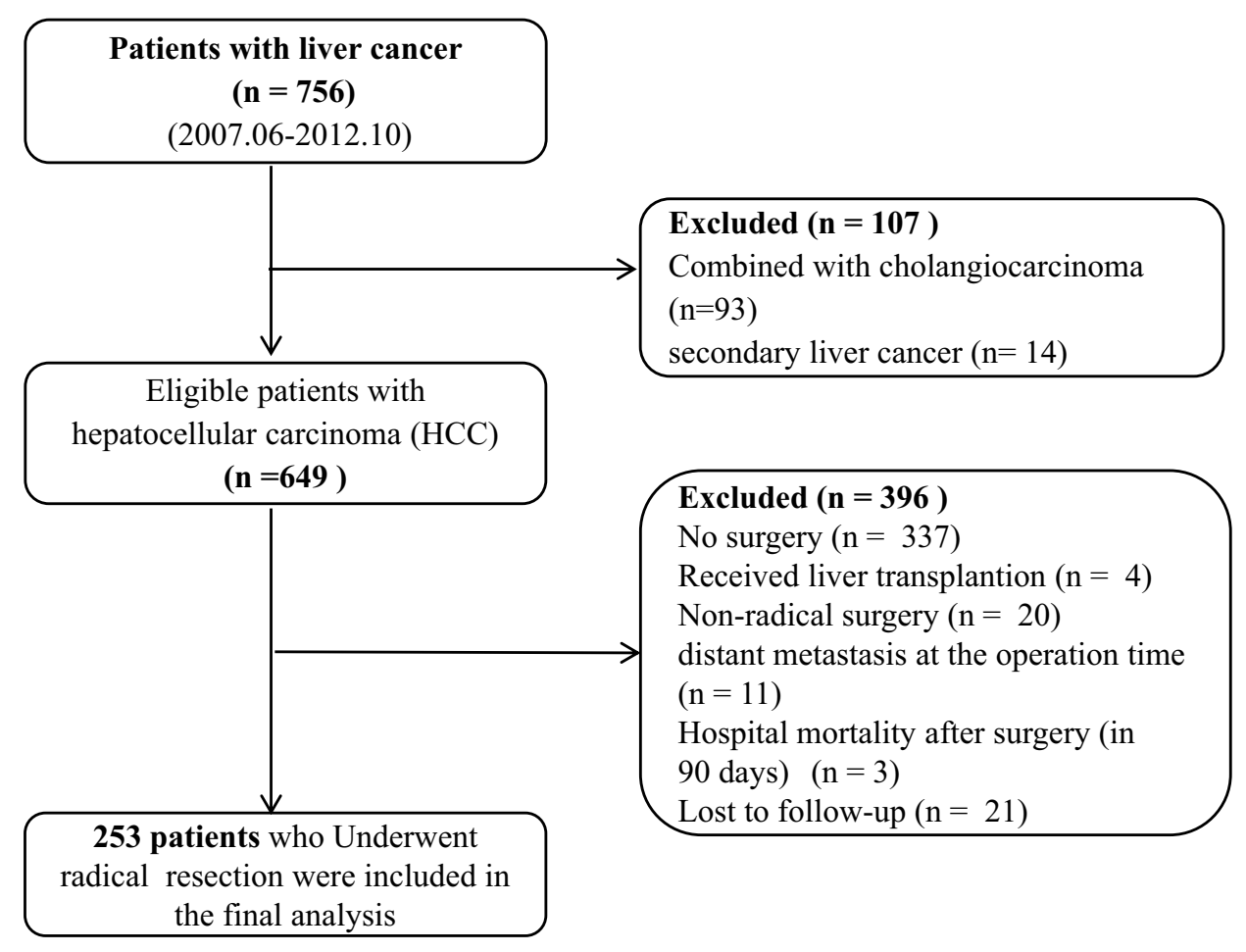

Figure I The flow chart shows the screening process of patients for inclusion in the study. 
University. Written informed consent was obtained from all patients.

\section{Data Collection and Follow-Up}

Data collection included basic demographic data, patients' previous diagnosis and treatment history, clinical physical examination results, preoperative serological examination results, imaging examination results (including US, MRI, $\mathrm{CT}$, etc.). All serological examinations (including blood routine, liver and kidney functions and AFP, etc.) of the patients were performed in the clinical laboratory department of the Affiliated Hospital of Guilin Medical University according to unified standards. The specific data collection content and principles are described in our previous study. ${ }^{18}$ All patients involved in the study received radical resection of HCC which was defined as complete resection of the tumor with a resection margin of at least $1 \mathrm{~cm}$, and no new lesions were found at the observation site with an interval of no less than 4 weeks. ${ }^{19}$ Postoperative follow-up principles were the same as our previous studies. ${ }^{18}$ Disease-free survival (DFS) was defined from the date of surgery to the date of metastasis, recurrence, death or the last follow-up, taking the earliest onset as the cut-off point. Overall survival (OS) was defined from the date of surgery to the date of death or the last follow-up.

Neutrophil to lymphocyte ratio (NLR) and Systemic immune-inflammation index (SII) are important immunological indicators of liver cancer, which have been proven to be good predictors of postoperative survival of liver cancer. ${ }^{20,21} \mathrm{SII}=P \times N / L, \mathrm{NLR}=N / L, P, N$, and $L$ were the preoperative peripheral platelet, neutrophil, and lymphocyte counts, respectively.

\section{Receiver Operating Characteristic (ROC) Curve and Cut-off Value}

In this study, the ROC curve was introduced to determine the best cut-off value for predicting the postoperative prognosis of patients with liver cancer. ROC curve is a series of curves drawn with positive rate (sensitivity) as ordinate and false-positive rate (1-specificity) as abscissa according to different dichotomies. AUC (area under curve) is defined as the area under ROC curve. The value range of AUC is between 0.5 and 1 . The closer AUC is to 1.0, the more accurate the model is. By analyzing the sensitivity and specificity values of each point on the curve, an optimal cut-off value can be determined, under which serum iron has the best sensitivity and specificity for postoperative prediction of patients.

\section{Data Analysis}

The MedCalc statistical software version 11.3.0.0, combined with the subject operating characteristic (ROC) curve, were used to determine the optimal cut-off value for the assessment of HCC survival outcomes with serum iron. SPSS 24.0 software was used for statistical data analysis. Continuous variables conforming to the normal distribution were expressed as mean \pm standard deviation (SD) and assessed with Student's $t$-test. The classified data were compared by Pearson chi-square test or Fish exact test. Correlation analysis was used to evaluate the relationship between preoperative serum iron levels and other clinicopathological indicators in HCC patients. KaplanMeier method and log rank test were used to analyze the OS, DFS and recurrence rate of patients. Univariate analysis and multivariate COX hazards regression model were used to determine the prognostic factors related to OS and DFS. $P<0.05$ was considered statistically significant.

\section{Results}

\section{Patient Characteristics}

The basic clinicopathological characteristics of the patients are listed in Table 1. Baseline levels of major hematological

Table I Clinical and Biochemical Data of Examined Patients

\begin{tabular}{|l|l|}
\hline Parameter & Mean \pm SD* \\
\hline Age (years) & $50.44 \pm 11.04$ \\
Gender: female/male $(\mathrm{n})$ & $31 / 222$ \\
HBsAg: positive/negative $(\mathrm{n})$ & $213 / 40$ \\
Tumor size (range, cm) & $7.46 \pm 4.28$ \\
Cirrhosis: yes/no $(\mathrm{n})$ & $237 / 16$ \\
WBC $\left(\times 10^{9} / \mathrm{L}\right)$ & $6.22 \pm 2.07$ \\
LYMPH $\left(\times 10^{9} / \mathrm{L}\right)$ & $1.69 \pm 0.63$ \\
Platelets $\left(\times 10^{9} / \mathrm{L}\right)$ & $185.12 \pm 76.77$ \\
Albumin $(g / \mathrm{L})$ & $38.01 \pm 4.42$ \\
Globulin $(g / \mathrm{L})$ & $32.19 \pm 5.84$ \\
TB $(\mu \mathrm{mol} / \mathrm{L}):$ median, range & $12.89(3.72-186.3)$ \\
DB $(\mu \mathrm{mol} / \mathrm{L}):$ median, range & $4.61(0.48-132.2)$ \\
ALT $(\mathrm{U} / \mathrm{L})$ & $46.29 \pm 44.37$ \\
AST $(\mathrm{U} / \mathrm{L})$ & $50.47 \pm 42.86$ \\
ALP $(\mathrm{U} / \mathrm{L})$ & $100.63 \pm 69.82$ \\
AFP $(\mathrm{ng} / \mathrm{mL}):$ median, range & $267.5(0.23-24,200)$ \\
NLR & $2.52 \pm 2.14$ \\
SIl & $478.95 \pm 412.09$ \\
Serum iron $(\mu g / d L)$ & $89.73 \pm 43.87$ \\
\hline
\end{tabular}

Note: *Data presented as mean \pm SD or others.

Abbreviations: SD, standard deviation; $N$, number of patients; $H B s A g$, hepatitis B surface antigen; AFP, alpha-fetoprotein; WBC, white blood cell; LYMPH, lymphocyte count; TB, total bilirubin; DB, direct bilirubin; ALT, alanine aminotransferase; AST, aspartate aminotransferase; ALP, alkaline phosphatase; NLR, neutrophil to lymphocyte ratio; SII, systemic immune-inflammation index. 
indexes were as follows: alanine aminotransferase (ALT) was $46.29 \pm 44.37(\mathrm{U} / \mathrm{L})$, aspartate amino transferase (AST) was $50.47 \pm 42.86(\mathrm{U} / \mathrm{L})$, alkaline phosphatase (ALP) was 100.63 $\pm 69.82(\mathrm{U} / \mathrm{L})$, AFP was 267.5 (0.23-24,200) (ng/mL), NLR was $2.52 \pm 2.14$, SII $478.95 \pm 412.09(\%, \mathrm{SII}=\mathrm{P} \times \mathrm{N} / \mathrm{L})$, iron was $89.73 \pm 43.87(\mu \mathrm{g} / \mathrm{dL})$, etc.

\section{The Optimal Cut-off Value of Serum Iron}

According to ROC curve analysis, the AUC area of serum iron is $0.729(95 \% \mathrm{CI}, 0.670-0.783)$ in predicting the prognosis of HCC after operation. On this curve, the optimal cut-off value of preoperative serum iron level was $94 \mu \mathrm{g} / \mathrm{dL}$, the sensitivity was $71.8 \%$ and the specificity was $64.3 \%$ (Figure 2 ). In addition, based on this cutoff value, patients were divided into the high serum iron group (serum iron level $>94 \mu \mathrm{g} / \mathrm{dL}, \mathrm{n}=109$ ) and low serum iron group (serum iron level $\leq 94 \mu \mathrm{g} / \mathrm{dL}, \mathrm{n}=144$ ).

\section{Relationship Between Serum Iron and Clinicopathological Parameters Associated with HCC}

The relationship between preoperative serum iron level and the clinicopathological parameters of HCC is shown in Table 2. The results showed that serum iron level was negatively correlated with tumor size $>5 \mathrm{~cm}\left(\chi^{2}=11.59, p<0.001\right)$, liver cancer TNM stage III-IV $\left(\chi^{2}=4.454, p=0.035\right)$, microvascular invasion $\left(\chi^{2}=5.087, p=0.024\right)$ and recurrence $\left(\chi^{2}=5.714\right.$,

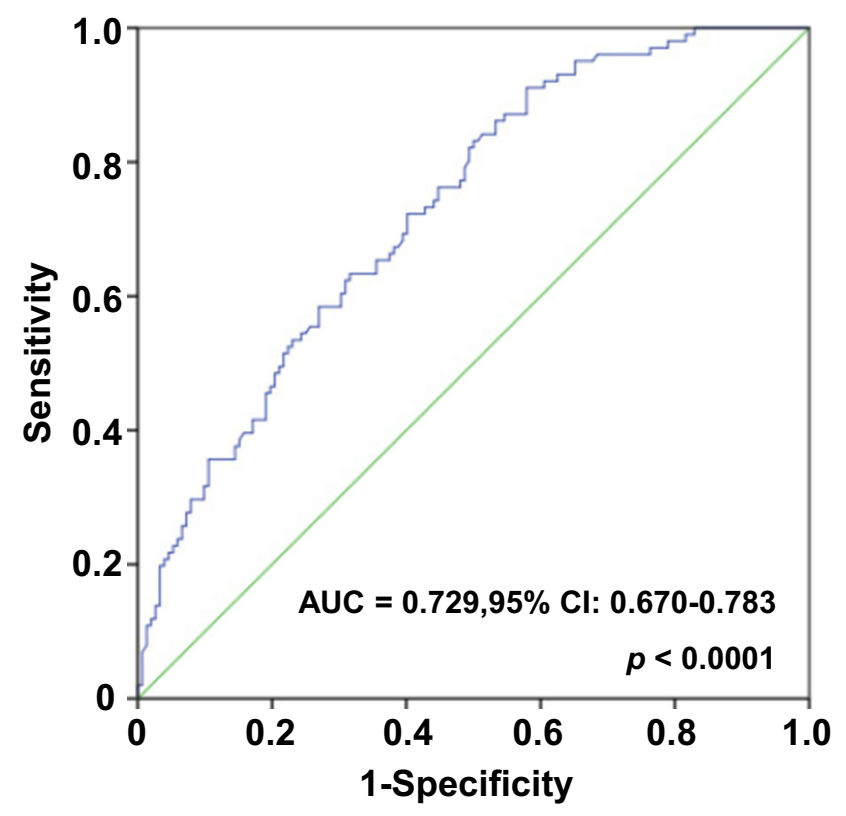

Figure 2 The ROC curve was performed to assess the prognostic value of preoperative serum iron of HCC. $p=0.017)$. However, there was no significant correlation with gender, age, hepatitis B surface antigen, tumor number, alcohol consumption, AFP, etc. (all $p>0.05$ ). As shown in Figure 3, patients with tumor size $\leq 5 \mathrm{~cm}$, TNM I-II period, no microvascular invasion and no recurrence had higher serum iron levels. These results suggested that low serum iron levels were more likely to promote liver cancer progression, invasion and poor prognosis.

\section{Serum Iron Was Negatively Correlated with Inflammatory Markers in HCC Patients}

The correlation between serum iron level of HCC patients and SII as well as NLR is shown in Figure 4, the serum iron level was negatively correlated with SII $(\mathrm{r}=-0.376$, $p<0.001)$ and NLR $(\mathrm{r}=-0.284, p<0.001)$. These results suggested that lower serum iron levels may contribute to the inflammatory microenvironment for tumor growth.

\section{Application Value of Serum Iron Level in Prognosis Analysis of HCC Patients After Radical Resection}

Kaplan-Meier method was used to analyze the survival of the patients, and it was found that the preoperative serum iron level affected the prognosis of the patients obviously. The postoperative recurrence rate of patients in the low serum iron group was higher than that in the high serum iron group $(p=0.025)$ (Figure 5A); the serum iron level in the recurrence group was lower than the group with no recurrence ( $p=$ 0.0013 ) (Figure 5B). In addition, OS and DFS were shorter in the low serum iron group than in the high serum iron group ( $p=0.001, p=0.011$ ) (Figure 6A and B). The mean values of OS and DFS in the high serum iron group were 58.71 and 48.28 months, respectively, while those in the low serum iron group were 46.78 and 36.65 months, respectively. The OS of the high/low serum iron groups in 1-, 3-, 5-, and 7-years were: 1 year $(92.7 \%$ vs $91.0 \%), 3$ years $(68.8 \%$ vs $55.6 \%), 5$ years $(52.8 \%$ vs $34.2 \%)$, and 7 years (44.3\% vs $27.8 \%$ ). These results suggested that serum iron level may be a potential indicator for postoperative assessment of HCC.

\section{Survival Analysis of AFP and Serum Iron Levels in Patients of SHCC Subgroup}

$\mathrm{HCC}$ with a diameter less than $3 \mathrm{~cm}$ was classified as small hepatocellular carcinoma (SHCC), and 45 patients from SHCC subgroup were involved in this part. According to the AFP level, SHCC patients were divided into high AFP group with AFP $>20 n g / m L ~(n=26)$ and low AFP group with AFP $\leq$ 
Table 2 Correlation Between the Clinicopathologic Variables and Serum Iron Level in HCC

\begin{tabular}{|c|c|c|c|c|c|c|}
\hline \multirow[t]{2}{*}{ Clinical Character } & \multirow[t]{2}{*}{ Clinical Variable } & \multirow[t]{2}{*}{ No. of Patients } & \multicolumn{2}{|l|}{ Iron Level } & \multirow[t]{2}{*}{$X^{2}$} & \multirow[t]{2}{*}{$p$-value } \\
\hline & & & $\leq 94$ No (\%) & $>94$ No (\%) & & \\
\hline Gender & $\begin{array}{l}\text { Female } \\
\text { Male }\end{array}$ & & & & & \\
\hline Age (years) & $\begin{array}{l}\leq 55 \\
>55\end{array}$ & $\begin{array}{l}167 \\
86\end{array}$ & $\begin{array}{l}99(59.3) \\
45(52.3)\end{array}$ & $\begin{array}{l}68 \text { (40.7) } \\
4 \mid(47.7)\end{array}$ & 1.12 & 0.29 \\
\hline $\mathrm{HBsAg}$ & $\begin{array}{l}\text { Negative } \\
\text { Positive }\end{array}$ & $\begin{array}{l}40 \\
213\end{array}$ & $\begin{array}{l}22(55) \\
122(57.3)\end{array}$ & $\begin{array}{l}18(45) \\
91(42.7)\end{array}$ & 0.71 & 0.79 \\
\hline Tumor size (range, $\mathrm{cm}$ ) & $\begin{array}{l}\leq 5 \\
>5\end{array}$ & $\begin{array}{l}104 \\
149\end{array}$ & $\begin{array}{l}46(44.2) \\
98(65.8)\end{array}$ & $\begin{array}{l}58(55.8) \\
51(34.2)\end{array}$ & 11.59 & 0.001 \\
\hline Tumor number & $\begin{array}{l}\text { Single } \\
\text { Multiple }\end{array}$ & $\begin{array}{l}198 \\
55\end{array}$ & $\begin{array}{l}\text { II } 3(57.1) \\
31 \text { (56.4) }\end{array}$ & $\begin{array}{l}85(42.9) \\
24(43.6)\end{array}$ & 0.009 & 0.925 \\
\hline Drinking & $\begin{array}{l}\text { Absent } \\
\text { Present }\end{array}$ & $\begin{array}{l}160 \\
93\end{array}$ & $\begin{array}{l}94(58.8) \\
50(53.8)\end{array}$ & $\begin{array}{l}66(4 I .3) \\
43(46.2)\end{array}$ & 0.596 & 0.44 \\
\hline TNM stage & $\begin{array}{l}\text { I-II } \\
\text { III-IV }\end{array}$ & $\begin{array}{l}120 \\
133\end{array}$ & $\begin{array}{l}60(50) \\
84(63.2)\end{array}$ & $\begin{array}{l}60(50) \\
49(36.8)\end{array}$ & 4.454 & 0.035 \\
\hline Microvascular invasion & $\begin{array}{l}\text { Absent } \\
\text { Present }\end{array}$ & $\begin{array}{l}176 \\
77\end{array}$ & $\begin{array}{l}92(52.3) \\
52(67.5)\end{array}$ & $\begin{array}{l}84(47.7) \\
25(32.5)\end{array}$ & 5.087 & 0.024 \\
\hline Recurrence & $\begin{array}{l}\text { Absent } \\
\text { Present }\end{array}$ & $\begin{array}{l}190 \\
63\end{array}$ & $\begin{array}{l}100(52.6) \\
44(69.8)\end{array}$ & $\begin{array}{l}90(47.4) \\
19(30.2)\end{array}$ & 5.714 & 0.017 \\
\hline $\operatorname{AFP}(\mathrm{ng} / \mathrm{mL})$ & $\begin{array}{l}\leq 20 \\
>20\end{array}$ & $\begin{array}{l}88 \\
165\end{array}$ & $\begin{array}{l}43(48.9) \\
101(6 I .2)\end{array}$ & $\begin{array}{l}45(51.5) \\
64(38.8)\end{array}$ & 3.569 & 0.059 \\
\hline AST (U/L) & $\begin{array}{l}\leq 40 \\
>40\end{array}$ & $\begin{array}{l}140 \\
113\end{array}$ & $\begin{array}{l}80(57.1) \\
64(56.6)\end{array}$ & $\begin{array}{l}60(42.9) \\
49(43.4)\end{array}$ & 0.007 & 0.936 \\
\hline
\end{tabular}

Note: $p$-value in bold indicates statistical significance.

Abbreviations: N, number of patients; HBsAg, hepatitis B surface antigen; TNM, tumor-node-metastasis; AFP, alpha-fetoprotein; AST, aspartate aminotransferase.

$20 \mathrm{ng} / \mathrm{mL}(\mathrm{n}=19)$. Kaplan-Meier analysis results of the two groups showed that there was no significant statistical difference in OS and DFS rates between the high AFP group and the low AFP group ( $p=0.953, p=0.941)$ (Figure 6C and 6D).

According to the serum iron levels of SHCC patients, the patients were divided into high serum iron group with serum iron $>94 \mu \mathrm{g} / \mathrm{dL}(\mathrm{n}=26)$ and low serum iron group with serum iron $\leq 94 \mu \mathrm{g} / \mathrm{dL}(\mathrm{n}=19)$. The mean values of OS and DFS in the high serum iron group were 75.94 and 71.11 months, respectively. The mean values of OS and DFS in the low serum iron group were 58.05 and 44.03 months, respectively. The OS of the high/low serum iron group in 1-, 3-, 5-, 7-years were: 1 year (1.00 vs 1.00), 3 years $(0.923$ vs 0.789$), 5$ years $(0.844$ vs 0.521$)$ and 7 years $(0.760$ vs 0.463$)$ ( $p=0.024$, Figure $6 \mathrm{E}$ and $\mathrm{F}$ ). In conclusion, serum iron is obviously better than AFP in predicting postoperative survival of patients with SHCC.

\section{Univariate and Multivariate Analysis for OS and DFS}

As shown in Table 3, the single factor analysis showed that HCC patients with high preoperative serum iron level had better OS [HR, 1.78; 95\% confidence interval (CI), 1.48-2.87; $p<0.001]$ and DFS (HR, 1.63; 95\% CI, $1.22-2.44 ; p=0.001)$ than that with low preoperative serum iron. In addition, patients with tumor size $<5 \mathrm{~cm}$, TNM I - II period, no recurrence, no microvascular invasion, AFP $<20 \mathrm{ng} / \mathrm{mL}$ and SII $<330 \mathrm{had}$ longer DFS and OS. Multivariate COX hazards regression analysis showed that, in addition to recurrence being an independent factor for poor OS prognosis, preoperative serum iron level $\leq 94 \mu \mathrm{g} / \mathrm{dL}$, tumor size $>5 \mathrm{~cm}$ and microvascular invasion were independent predictors for shorter OS and DFS in HCC patients (HR, 95\% CI and $p$-value was shown in Table 3). 
A

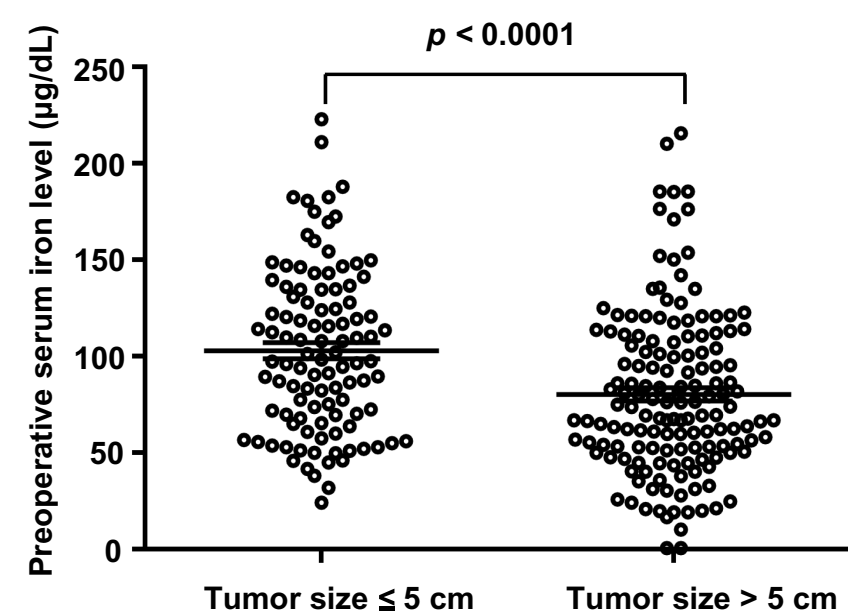

C

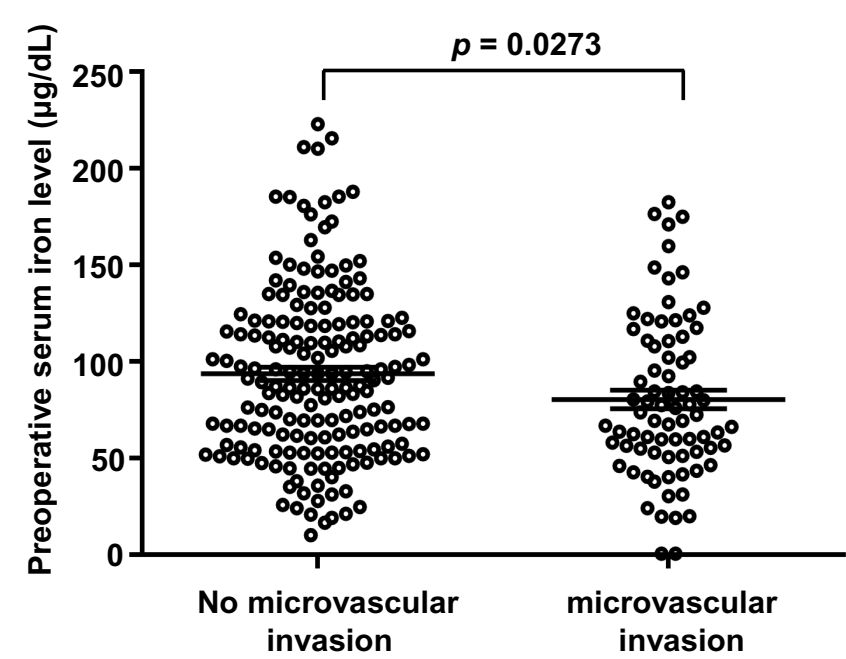

B

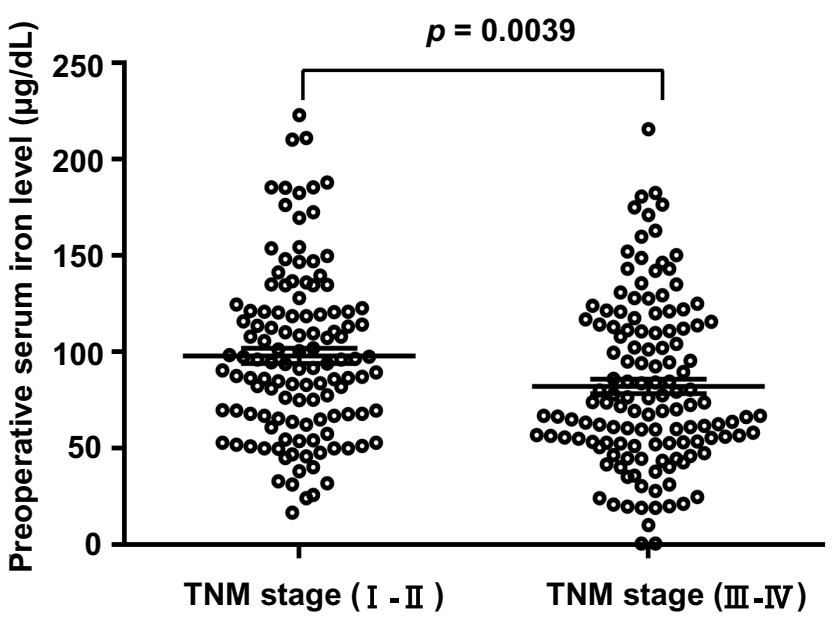

D

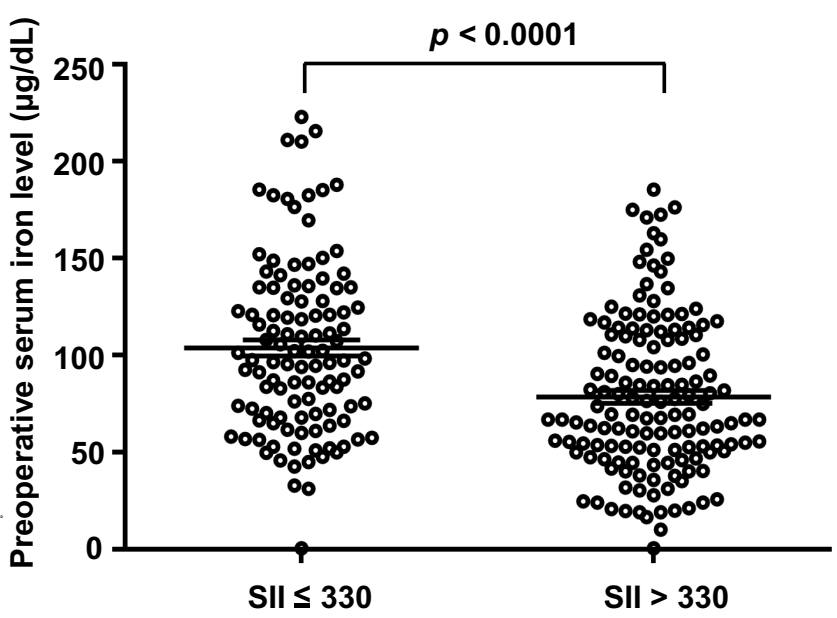

Figure 3 Classified scatter plots of serum iron levels according to tumor size (A), TNM stage (B), microvascular invasion (C) and SII (D). Abbreviations: TNM, tumor, node and metastases; SII, systemic immune-inflammation index.

\section{Discussion}

Currently, although some progress has been made in clinical diagnosis and treatment of HCC, the overall prognosis of HCC patients is still poor. ${ }^{3}$ Therefore, selecting appropriate preoperative biomarkers to accurately assess the prognosis and risk of recurrence can provide a more optimal treatment scheme for the treatment of HCC.

By analyzing the relation between clinicopathologic parameters and serum iron in $\mathrm{HCC}$, we found that low serum iron level was correlated with larger tumor, microvascular invasion, higher TNM classification and recurrence. All of the above indicators can affect or directly reflect the malignancy and prognosis of $\mathrm{HCC}$ patients, ${ }^{22,23}$ which indicates that serum iron level can be used as a potential prognostic indicator of HCC.

As a necessary microelement in human body, iron has been proven to play an important role in the occurrence of immune diseases. ${ }^{24}$ Iron ion protects RNA-binding protein PCBP1 from being cleaved and degraded by Caspase proteolytic enzymes, which can enhance the stability of target gene mRNA and promote the production of proinflammatory cytokines. ${ }^{25}$ This study found that serum iron was negatively correlated with inflammatory indicators such as SII and NLR. The results suggested that low serum iron may accelerate the progress of tumor microenvironment and promote the proliferation and migration of tumor cells. 

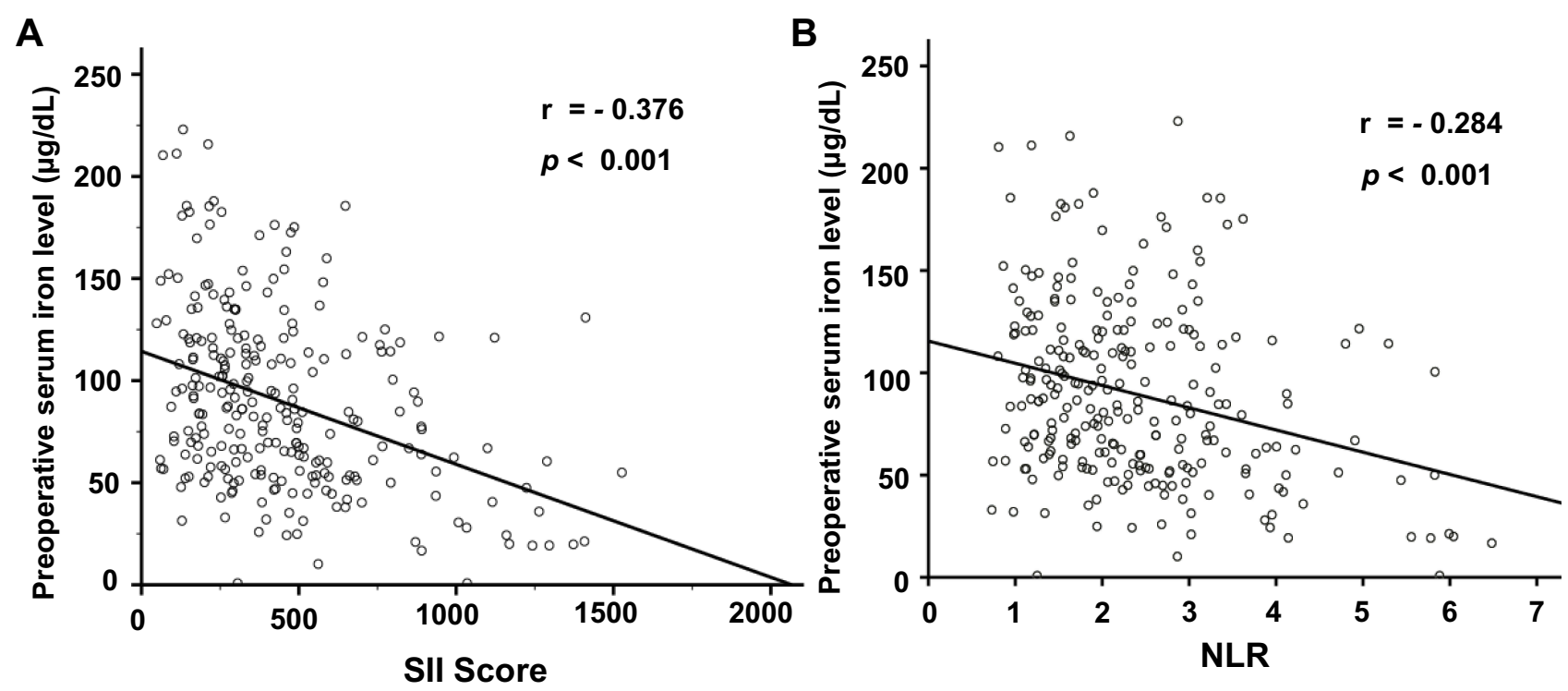

Figure 4 The scatter plot shows the relationship between serum iron and SIl as well as NLR.

Abbreviations: SII, systemic immune-inflammation index; NLR, neutrophil to lymphocyte ratio.
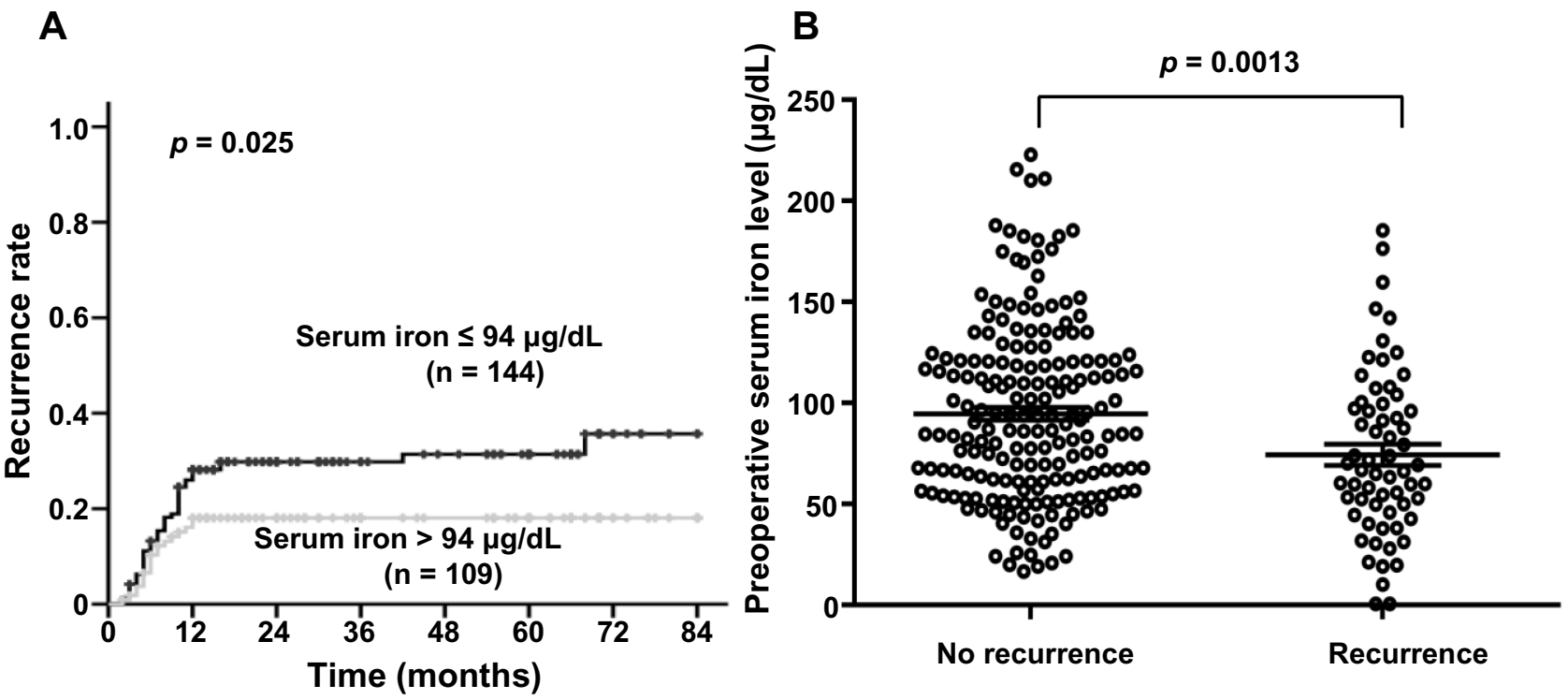

Figure 5 Comparison of postoperative recurrence rates between patients in the high serum iron group and those in the low serum iron group. Kaplan-Meier analysis revealed significantly higher recurrence rates in patients with serum iron $\leq 94 \mu \mathrm{g} / \mathrm{dL}$ than in those with serum iron $>94 \mu \mathrm{g} / \mathrm{dL}(\mathbf{A})$; classified scatter plots show the recurrence group had lower serum iron levels (B).

Currently, in this cohort study, our results' analysis showed that patients with preoperative serum iron content $\leq 94 \mu \mathrm{g} / \mathrm{dL}$ had higher recurrence rates and worse OS and DFS after surgery. This suggested that serum iron could be used as a biomarker to predict the post-operative status (including survival and recurrence rates) of HCC patients and to participate in the risk assessment of surgery. Interestingly, some studies had also found that high serum iron could increase the incidence and mortality of cancers, ${ }^{12,26}$ which was inconsistent with our results. It was speculated that too high or too low serum iron level was not conducive to the health of tumor patients, which meant that only at a reasonable level, serum iron could play a good role of health guard for tumor patients.

The epidemiological statistical studies of HCC showed that the postoperative survival time of SHCC patients with single cancer nodule whose maximum diameter was not more than $3 \mathrm{~cm}$ or two cancer nodules 

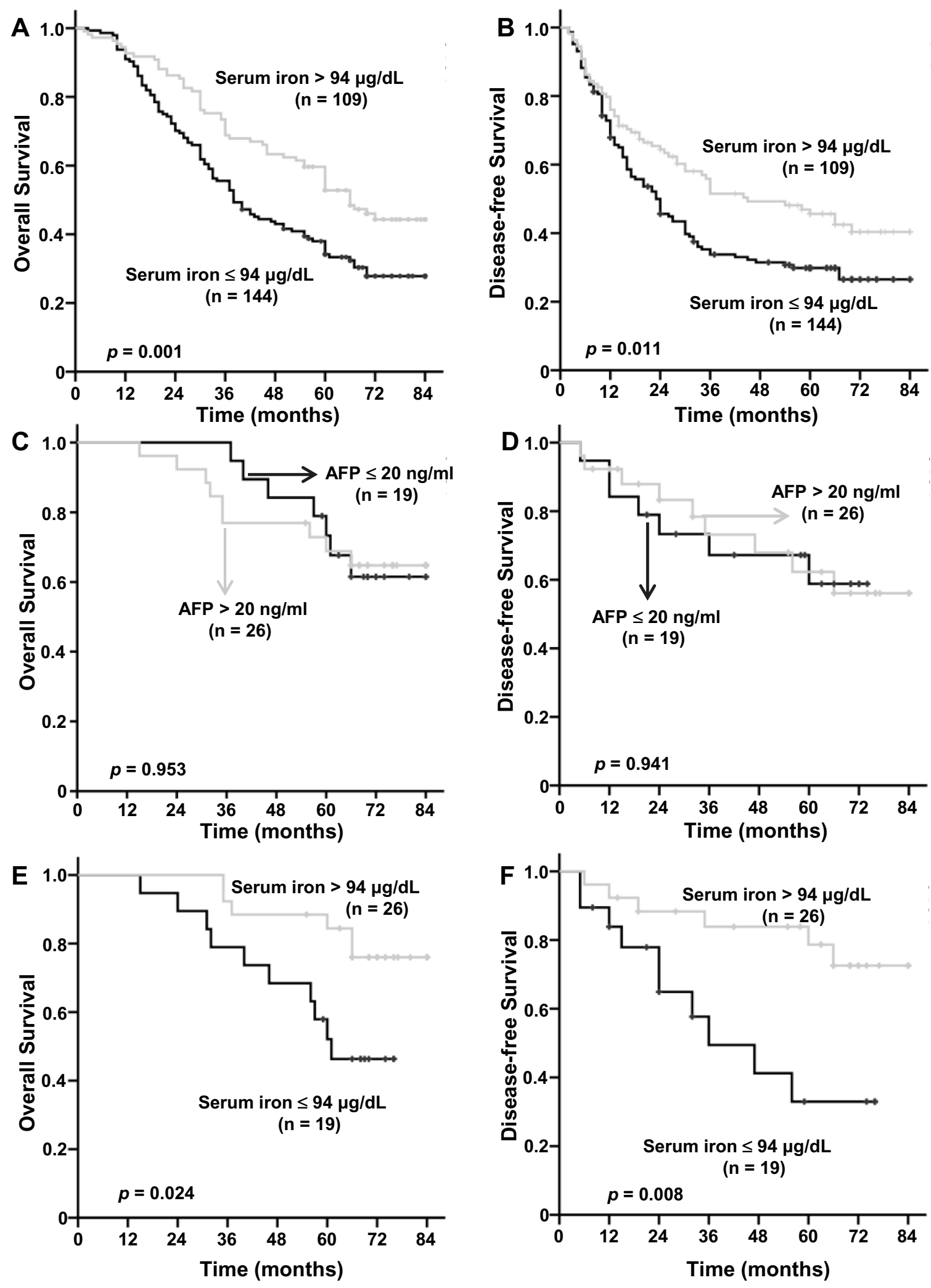

Figure 6 The relationship of serum iron level with OS or DFS.

Notes: (A, B) In the overall population, Kaplan-Meier analysis revealed significantly shorter OS (A) and DFS (B) in HCC patients with serum iron $\leq 94 \mu \mathrm{gg} / \mathrm{dL}$ than in those with serum iron $>94 \mu \mathrm{g} / \mathrm{dL}$. (C-F) In SHCC subgroup, no significant differences in OS (C) or DFS (D) are seen between AFP $\leq 20 \mathrm{ng} / \mathrm{mL}$ and AFP $>20 \mathrm{ng} / \mathrm{mL}$, OS (E) and DFS (F) of patients with serum iron $\leq 94 \mu \mathrm{g} / \mathrm{dL}$ were shorter than in those with serum iron $>94 \mu \mathrm{g} / \mathrm{dL}$. 
Table 3 Univariate and Multivariate Cox Regression Analyses of the Serum Iron with Clinicopathologic Characteristics

\begin{tabular}{|c|c|c|c|c|c|c|}
\hline \multirow[t]{2}{*}{ Variable } & \multicolumn{3}{|c|}{ Univariate Analysis } & \multicolumn{3}{|c|}{ Multivariate Analysis } \\
\hline & HR & $95 \% \mathrm{Cl}$ & $p$-value & HR & $95 \% \mathrm{Cl}$ & $p$-value \\
\hline \multicolumn{7}{|l|}{ Overall survival } \\
\hline Iron level ( $\leq 94$ vs $>94)$ & 1.87 & I.48-2.87 & $<0.001$ & 1.54 & $1.08-2.32$ & 0.021 \\
\hline Gender (male vs female) & 0.95 & $0.59-1.55$ & 0.848 & & & \\
\hline Age, yeas (>55 vs $\leq 55)$ & 0.82 & $0.58-1.14$ & 0.230 & & & \\
\hline HBsAg (positive vs negative) & 0.99 & $0.65-1.52$ & 0.982 & & & \\
\hline Tumor size, $\mathrm{cm}(>5$ vs $\leq 5)$ & 2.02 & $1.48-2.62$ & $<0.001$ & 1.15 & $0.82-1.63$ & 0.404 \\
\hline Tumor number (multiple vs single) & 1.13 & $0.78-1.63$ & 0.521 & & & \\
\hline Drinking (present vs absent) & 0.89 & $0.64-1.24$ & 0.494 & & & \\
\hline TNM stage (III-IV vs I-II) & 2.35 & $1.78-3.06$ & $<0.001$ & 1.72 & $1.13-2.60$ & 0.011 \\
\hline Recurrence (present vs absent) & 2.76 & $1.89-3.32$ & $<0.001$ & 2.21 & $1.59-2.86$ & 0.001 \\
\hline Microvascular invasion (present vs absent) & 1.81 & $1.44-2.65$ & $<0.001$ & 1.61 & $1.14-2.35$ & 0.008 \\
\hline AFP, ng/mL (>20 vs $\leq 20)$ & 1.72 & $1.43-2.32$ & 0.008 & 1.26 & $0.85-1.90$ & 0.249 \\
\hline SII, (>330 vs $\leq 330)$ & 1.59 & $1.15-2.08$ & 0.004 & 1.05 & $0.68-1.61$ & 0.818 \\
\hline \multicolumn{7}{|l|}{ Progression-free survival } \\
\hline Iron level ( $\leq 94$ vs >94) & 1.63 & I.22-2.44 & 0.001 & 1.52 & $1.03-2.15$ & 0.032 \\
\hline Gender (male vs female) & 0.93 & $0.58-1.5 \mid$ & 0.793 & & & \\
\hline Age, yeas (>55 vs $\leq 55)$ & 0.84 & $0.60-1.17$ & 0.317 & & & \\
\hline HBsAg (positive vs negative) & 1.01 & $0.66-1.56$ & 0.935 & & & \\
\hline Tumor size, $\mathrm{cm}$ ( $>5$ vs $\leq 5)$ & 1.78 & $1.35-2.64$ & $<0.001$ & 1.09 & $0.77-1.56$ & 0.639 \\
\hline Tumor number (multiple vs single) & 1.20 & $0.83-1.74$ & 0.331 & & & \\
\hline Drinking (present vs absent) & 0.93 & $0.67-1.29$ & 0.665 & & & \\
\hline TNM stage (III-IV vs I-II) & 2.12 & $1.52-2.50$ & $<0.001$ & 1.77 & $1.16-2.66$ & 0.007 \\
\hline Microvascular invasion (present vs absent) & 1.66 & $1.23-2.32$ & 0.001 & 1.78 & $1.32-2.50$ & $<0.001$ \\
\hline AFP, $\mathrm{ng} / \mathrm{mL}(>20$ vs $\leq 20)$ & 1.60 & $1.36-2.08$ & 0.021 & 1.03 & $0.69-1.55$ & 0.887 \\
\hline SII, $(>330$ vs $\leq 330)$ & 1.45 & $1.05-1.99$ & 0.023 & 1.03 & $0.70-1.56$ & 0.875 \\
\hline
\end{tabular}

Note: $p$-value in bold indicates statistical significance.

Abbreviations: HR, hazard ratio; $\mathrm{Cl}$, confidence interval; $\mathrm{HBsAg}$, hepatitis B surface antigen; TNM, tumor-node-metastasis; AFP, alpha-fetoprotein; SII, systemic immuneinflammation index.

whose total diameter was not more than $3 \mathrm{~cm}$, was better than that of other types of liver cancer clearly. ${ }^{27,28}$ Therefore, the postoperative prognosis assessment of SHCC subgroup patients was of great clinical significance. The results of postoperative follow-up of SHCC subgroup patients in this study showed that the postoperative survival time in the high iron group was better than that in the low iron group markedly. Although AFP as the most widely used biochemical diagnostic indicator of HCC in clinical practice, OS and DFS of SHCC patients involved in this study had no significant difference in AFP level $(p>0.05)$. The results were consistent with the conclusion in previous studies that AFP had limited ability to diagnosis and predict the prognosis of SHCC. Therefore, preoperative serum iron levels can be regarded as a biomarker for predicting the prognosis of early HCC.
However, the study still has unavoidable defects, the selection of subjects involved in the experiment has regional limitations. In the following studies, multi-center and multi-level prospective analysis can be adopted to minimize the biases of recruitment and follow-up, so as to provide a basis for improving the precise prognosis of HCC. In addition, the results of this study have not been verified by experiments in other aspects except retrospective analysis. In subsequent studies, corresponding animal models can be constructed to determine the prognosis of model animals by changing the serum iron content in animals, improving the scientific nature of the study from different perspectives.

\section{Conclusion}

Our results showed that patients with low preoperative serum iron level had worse postoperative survival and 
higher recurrence rate in HCC. Preoperative serum iron is an independent predictor for HCC. Serum iron also had a good predictive ability for prognosis of patients with SHCC. Serum iron could be involved in the comprehensive assessment of postoperative risk of HCC patients, which is of guiding significance for the selection of treatment methods for HCC patients, and helps to improve the rationality of clinical operation selection. For HCC patients with low serum iron level, appropriate iron supplementation may improve the prognosis of patients.

\section{Acknowledgments}

We are grateful to the patients participate in this study and all the staff in the hepatobiliary surgery department of the Affiliated Hospital of Guilin Medical University for their support and cooperation in making this study completed successfully.

\section{Author Contributions}

All authors contributed to data analysis, drafting or revising the article, gave final approval of the version to be published, and agree to be accountable for all aspects of the work.

\section{Funding}

This work was supported in part by the National Natural Science Foundation of China (No. 81773148), the National Key Sci-Tech Special Project of China (No. 2018ZX103 02207) and the Natural Science Foundation of Guangxi (No. 2018GXNSFDA138001).

\section{Disclosure}

The authors report no conflicts of interest in this work.

\section{References}

1. Bray F, Ferlay J, Soerjomataram I, et al. Global cancer statistics 2018: GLOBOCAN estimates of incidence and mortality worldwide for 36 cancers in 185 countries. CA Cancer J Clin. 2018;68(6):394-424. doi: $10.3322 /$ caac.v68.6

2. Maluccio M, Covey A. Recent progress in understanding, diagnosing, and treating hepatocellular carcinoma. CA Cancer J Clin. 2012;62 (6):394-399. doi:10.3322/caac.21161

3. Altekruse SF, McGlynn KA, Dickie LA, Kleiner DE. Hepatocellular carcinoma confirmation, treatment, and survival in surveillance, epidemiology, and end results registries, 1992-2008. Hepatology. 2012;55(2):476-482. doi:10.1002/hep.24710

4. Yang SL, Liu LP, Yang S, et al. Preoperative serum alpha-fetoprotein and prognosis after hepatectomy for hepatocellular carcinoma. $\mathrm{Br}$ J Surg. 2016;103(6):716-724. doi:10.1002/bjs.10093

5. Giannini EG, Marenco S, Borgonovo G, et al. Alpha-fetoprotein has no prognostic role in small hepatocellular carcinoma identified during surveillance in compensated cirrhosis. Hepatology. 2012;56 (4):1371-1379. doi:10.1002/hep.v56.4
6. Bialecki ES, Ezenekwe AM, Brunt EM, et al. Comparison of liver biopsy and noninvasive methods for diagnosis of hepatocellular carcinoma. Clin Gastroenterol Hepatol. 2006;4(3):361-368. doi:10.1016/S1542-3565(05)00977-8

7. Farinati F, Marino D, De Giorgio M, et al. Diagnostic and prognostic role of alpha-fetoprotein in hepatocellular carcinoma: both or neither? $\mathrm{Am}$ J Gastroenterol. 2006;101(3):524-532. doi:10.1111/ajg.2006.101.issue-3

8. Torti SV, Torti FM. Iron and cancer: more ore to be mined. Nat Rev Cancer. 2013;13(5):342-355. doi:10.1038/nrc3495

9. Ioannou GN, Rockey DC, Bryson CL, Weiss NS. Iron deficiency and gastrointestinal malignancy: a population-based cohort study. $\mathrm{Am}$ J Med. 2002;113(4):276-280. doi:10.1016/S0002-9343(02)01214-7

10. Anderson GJ, Frazer DM. Current understanding of iron homeostasis. Am J Clin Nutr. 2017;106(Supp16):1559S-1566S. doi:10.3945/ajen.117.155804

11. Lonnerdal B. Excess iron intake as a factor in growth, infections, and development of infants and young children. Am J Clin Nutr. 2017;106 (Supp16):1681S-1687S. doi:10.3945/ajcn.117.156042

12. Stevens RG, Graubard BI, Micozzi MS, Neriishi K, Blumberg BS. Moderate elevation of body iron level and increased risk of cancer occurrence and death. Int $J$ Cancer. 1994;56(3):364-369. doi:10.1002/(ISSN)1097-0215

13. Toyokuni S. Role of iron in carcinogenesis: cancer as a ferrotoxic disease. Cancer Sci. 2009;100(1):9-16. doi:10.1111/j.1349-7006.2008.01001.x

14. Zhou XJ, Laszik Z, Wang XQ, Silva FG, Vaziri ND. Association of renal injury with increased oxygen free radical activity and altered nitric oxide metabolism in chronic experimental hemosiderosis. Lab Invest. 2000;80(12):1905-1914. doi:10.1038/labinvest.3780200

15. Stockwell BR, Friedmann Angeli JP, Bayir H, et al. Ferroptosis: a regulated cell death nexus linking metabolism, redox biology, and disease. Cell. 2017;171(2):273-285. doi:10.1016/j.cell.2017.09.021

16. Wei Y, Ye W, Zhao W. Serum iron levels decreased in patients with HBV-related hepatocellular carcinoma, as a risk factor for the prognosis of HBV-related HCC. Front Physiol. 2018;9:66. doi:10.3389/ fphys.2018.00066

17. Kato J, Miyanishi K, Kobune M, et al. Long-term phlebotomy with low-iron diet therapy lowers risk of development of hepatocellular carcinoma from chronic hepatitis C. J Gastroenterol. 2007;42 (10):830-836. doi:10.1007/s00535-007-2095-z

18. Liao Y, Yuan S, Chen X, et al. Up-regulation of BRCA1-associated RING domain 1 promotes hepatocellular carcinoma progression by targeting akt signaling. Sci Rep. 2017;7(1):7649. doi:10.1038/s41598-017-07962-7

19. Chen Q, Shu C, Laurence AD, et al. Effect of Huaier granule on recurrence after curative resection of HCC: a multicentre, randomised clinical trial. Gut. 2018;67(11):2006-2016. doi:10.1136/gutjnl-2018-315983

20. Mano Y, Shirabe K, Yamashita Y, et al. Preoperative neutrophil-tolymphocyte ratio is a predictor of survival after hepatectomy for hepatocellular carcinoma: a retrospective analysis. Ann Surg. 2013;258(2):301-305. doi:10.1097/SLA.0b013e318297ad6b

21. Hu B, Yang XR, Xu Y, et al. Systemic immune-inflammation index predicts prognosis of patients after curative resection for hepatocellular carcinoma. Clin Cancer Res. 2014;20(23):6212-6222. doi:10.1158/1078-0432.CCR-14-0442

22. Wu G, Wu J, Wang B, Zhu X, Shi X, Ding Y. Importance of tumor size at diagnosis as a prognostic factor for hepatocellular carcinoma survival: a population-based study. Cancer Manag Res. 2018;10:4401-4410. doi: $10.2147 / \mathrm{CMAR}$

23. Cucchetti A, Piscaglia F, Grigioni AD, et al. Preoperative prediction of hepatocellular carcinoma tumour grade and micro-vascular invasion by means of artificial neural network: a pilot study. $J$ Hepatol. 2010;52(6):880-888. doi:10.1016/j.jhep.2009.12.037

24. Gutschow P, Schmidt PJ, Han H, et al. A competitive enzyme-linked immunosorbent assay specific for murine hepcidin-1: correlation with hepatic mRNA expression in established and novel models of dysregulated iron homeostasis. Haematologica. 2015;100(2):167-177. doi:10. 3324/haematol.2014.116723 
25. Wang Z, Yin $\mathrm{W}$, Zhu L, et al. Iron drives T helper cell pathogenicity by promoting RNA-binding protein PCBP1-mediated proinflammatory cytokine production. Immunity. 2018;49(1):80-92.e7. doi:10.1016/j.immuni. 2018.05.008

26. Wen CP, Lee JH, Tai YP, et al. High serum iron is associated with increased cancer risk. Cancer Res. 2014;74(22):6589-6597. doi:10.1158/0008-5472.CAN-14-0360

27. Zhang W, Wang X, Jiang R, et al. Effect of tumor size on cancer-specific survival in small hepatocellular carcinoma. Mayo Clin Proc. 2015;90 (9):1187-1195. doi:10.1016/j.mayocp.2015.06.018
28. Poon RT, Fan ST, Lo CM, Liu CL, Wong J. Long-term survival and pattern of recurrence after resection of small hepatocellular carcinoma in patients with preserved liver function: implications for a strategy of salvage transplantation. Ann Surg. 2002;235 (3):373-382. doi:10.1097/00000658-200203000-00009

\section{Publish your work in this journal}

Cancer Management and Research is an international, peer-reviewed open access journal focusing on cancer research and the optimal use of preventative and integrated treatment interventions to achieve improved outcomes, enhanced survival and quality of life for the cancer patient.
The manuscript management system is completely online and includes a very quick and fair peer-review system, which is all easy to use. Visit http://www.dovepress.com/testimonials.php to read real quotes from published authors. 